\title{
RECOMMENDATIONS FOR THE DEVELOPMENT OF REGULATORY GUIDELINES FOR REGISTRATION OF TRADITIONAL MEDICINES IN SOUTH AFRICA
}

\author{
Ngcobo, M. ${ }^{\mathrm{a}}$, Nkala, B. ${ }^{\mathrm{a}}$, Moodley, $\mathrm{I}^{\mathrm{a}, \mathrm{b}}$, and * Gqaleni, N. ${ }^{\mathrm{a}}$ \\ ${ }^{\mathrm{a}}$ Traditional Medicine Laboratory, Department of Occupational \& Environmental Health, ${ }^{\mathrm{b}}$ Department of \\ Public Health Medicine, Nelson R Mandela School of Medicine, University of KwaZulu-Natal Durban, \\ South Africa. \\ *E-mail: gqalenin@ukzn.ac.za
}

\begin{abstract}
The regulation and registration of traditional medicines (TM) continues to present challenges to many countries regardless of the fact that an increased number of the population utilises TM for their health care needs. There have been improvements in the legal and policy framework of South Africa based on the WHO guidelines. However, there are currently no guidelines or framework for the registration of TM in South Africa. This article reviews literature and existing guidelines of specific countries and regions and makes recommendations for South African guidelines.
\end{abstract}

Keywords: Regulation, Registration, Traditional Medicines, South Africa

\section{Introduction}

Traditional medicines (TM) and plant-based remedies are widely used in Africa. It has been estimated that $80 \%$ of the African population relies on traditional forms of medicine to meet their healthcare needs (World Health Organisation (WHO), 2004). Worldwide the trend has also shifted towards the use of TM due to concerns about the costs, invasiveness and potential for toxicity of conventional mainstream remedies (Cowan, 1999). Most of these TM are not well-researched, poorly regulated, may contain adulterated products, and may produce adverse effects (Mills et al., 2005). Traditional medicines are defined as the sum total of knowledge, skills and practices based on the theories, beliefs and experiences indigenous to different cultures, whether explicable or not, used in the maintenance of health as well as in prevention, diagnosis, improvement or treatment of physical or mental illnesses (WHO, 2001). Over the last fifteen years the safety and efficacy of TM, as well as quality control, have become important concerns for both health authorities and the public (WHO, 2005).

It is important to identify that various practices exist in different cultures of the world, and therefore it would be difficult to develop uniform regulations for registration of TM. A 2005 survey of the WHO on national policy on traditional medicine and regulation of herbal medicines in member countries identified a lot of challenges in the development of such regulations. These range from regulatory status, safety and efficacy assessment, quality control and standardisation, safety monitoring and lack of knowledge about traditional, complementary and alternative medicines (TCAM) by relevant national drug regulatory authorities (WHO, 2005). Implementation of such regulatory matters in developing countries where TM still form the backbone of the healthcare systems is also hampered by lack of resources.

The TM law of each country should include and define the regulatory status, claim types, pharmacopoeia and monographs used, manufacturing requirements and control mechanisms, safety requirements, registration systems, etc. Basically the regulations are drafted to implement the National Policy on TM (WHO, 2005). South Africa has taken various initiatives to promote the regulation of TM and its practices. The national drug policy which includes TCAM was developed in 1996. The Policy recognizes the potential role of and benefits of available remedies of TM in the National Health System. It is aimed at investigating the use of effective and safe TM at primary level. It further stipulates; (1) the investigation of TM for efficacy, safety and quality with the aim to incorporate their use in the national health care delivery system and, (2) registration and control of marketed TM. Other initiatives include the establishment of two expert committees on African TM and CAM, to advise the Medicines Control Council (MCC) (Gqaleni et al., 2007).

Unfortunately the regulatory framework for registration of TM specifically designed to provide the legal machinery to achieve the administrative and technical goals of the National Policy is still under development. The national pharmacopoeia and monographs on herbal medicines are also still in development. Manufacturing and safety assessment requirements are similar to good manufacturing practice (GMP) rules as those used by conventional pharmaceuticals. According to the WHO survey on regulation of TM and, specifically, herbal medicines showed that $65 \%$ of Member States have laws or regulations on herbal medicines and these regulations are largely similar to those of conventional medicines. Out of these, $61 \%$ reported that they have registration systems for herbal medicines (WHO, 2005). South Africa, as a country still developing its regulations, can learn a lot from these countries with regulations and registration systems for herbal medicines.

In developing regulations for registration of herbal medicines in South Africa, it is important to take into consideration the uniqueness of the TM systems in this country and then compare it with those countries with developed regulations. The guidelines to be developed by the MCC expert committee must also be guided by the WHO guidelines for registration of traditional and complementary medicines in the African region, which South Africa adopted as a member state (WHO, 2004). 
Table 1: A summary of regulatory guidelines for registration of traditional medicines (TM) in different countries and regions of the world (FDA, 2006; EMEA,2006 ${ }^{1,2}$; Deal,2010;

\begin{tabular}{|c|c|c|c|c|}
\hline $\begin{array}{l}\text { Requirements for } \\
\text { registration of TM }\end{array}$ & $\begin{array}{l}\text { Food and DrugAdministration } \\
\text { (United States of America) }\end{array}$ & $\begin{array}{c}\begin{array}{c}\text { European Medicines Agency } \\
\text { (European Union) }\end{array} \\
\end{array}$ & $\begin{array}{c}\text { Australian Guidelines for } \\
\text { Complementary Medicines } \\
\end{array}$ & $\begin{array}{c}\text { WHO Guidelines for registration of } \\
\text { TM in African region }\end{array}$ \\
\hline Traditional use & Not considered & $\begin{array}{l}\text { Traditional use does not substitute } \\
\text { quality. Bibliographical evidence of } \\
\text { traditional use must be presented }\end{array}$ & $\begin{array}{l}\text { Use of TM must be well established and } \\
\text { widely acknowledge; effective preparation, } \\
\text { dosage, method of use and indications are } \\
\text { well established; botanical identification of } \\
\text { herbal substance(s) }\end{array}$ & $\begin{array}{l}\text { Traditional use not addressed directly but } \\
\text { it is considered in evaluation of safety \& } \\
\text { efficacy of TM }\end{array}$ \\
\hline $\begin{array}{l}\text { Pharmaceutical } \\
\text { Quality }\end{array}$ & As conventional drugs & $\begin{array}{l}\text { Starting materials must be defined } \\
\text { by botanical identification and } \\
\text { quality must adhered to until the } \\
\text { final herbal product }\end{array}$ & $\begin{array}{l}\text { Each ingredient in formulation should be } \\
\text { characterized; state the plant part used and } \\
\text { processing before use in manufacture of the } \\
\text { product; brief description of manufacturing } \\
\text { process must be provided }\end{array}$ & $\begin{array}{l}\text { Raw plant material(s) should identified; } \\
\text { state plant part used; chemical, physical } \\
\& \text { biological tests for general } \\
\begin{array}{l}\text { identification; finished product } \\
\text { qualitatively \& quantitatively analysed }\end{array}\end{array}$ \\
\hline Stability Testing & As conventional drugs & $\begin{array}{l}\text { Stability should be determined by } \\
\text { appropriate } \\
\text { chromatograms }\end{array}$ & $\begin{array}{l}\text { Stability data must be sufficient to } \\
\text { demonstrate that the product intended for } \\
\text { market will remain safe, of consistent } \\
\text { quality and efficacious throughout its shelf } \\
\text { life. Maximum permitted shelf life is } 5 \\
\text { years }\end{array}$ & $\begin{array}{l}\text { Stability tests fall under quality } \\
\text { evaluation of raw \& finished product }\end{array}$ \\
\hline Safety & As conventional drugs & $\begin{array}{l}\text { Bibliographical evidence of safety } \\
\text { including cross-referencing to } \\
\text { Expert report. Safety summary } \\
\text { including herbal ingredients, use in } \\
\text { pregnancy \& lactation and possible } \\
\text { drug interactions must be included }\end{array}$ & $\begin{array}{l}\text { Traditional use not a substitute for safety. } \\
\text { Long-term and safe therapeutic use will be } \\
\text { considered in evaluating the safety of } \\
\text { products. Safety summary including herbal } \\
\text { ingredients, use in pregnancy \& lactation } \\
\text { and possible drug interactions must be } \\
\text { included }\end{array}$ & $\begin{array}{l}\text { Botanical authentication of raw plant(s); } \\
\text { biological information obtained via } \\
\text { literature/database search; standard } \\
\text { toxicological studies mandatory even of } \\
\text { long-term use history is available }\end{array}$ \\
\hline $\begin{array}{l}\text { Therapeutic } \\
\text { Efficacy }\end{array}$ & As conventional drugs & $\begin{array}{l}\text { Efficacy must be plausible on the } \\
\text { long-standing use and experience }\end{array}$ & $\begin{array}{l}\text { Traditional use will be taken into account } \\
\text { when establishing efficacy. Where } \\
\text { traditional use is not sufficient, clinical } \\
\text { evidence data should be provided. }\end{array}$ & $\begin{array}{l}\text { Efficacy dependent on kind of indications } \\
\text { for use \& individual experiences of } \\
\text { doctors, THPs or patients. Clinical } \\
\text { evidence is required traditionally-use } \\
\text { plants for a new indication. Active } \\
\text { ingredients should be standardised if } \\
\text { known; if actives are not, whole TM } \\
\text { should be taken active ingredient. }\end{array}$ \\
\hline $\begin{array}{l}\text { Labeling and } \\
\text { packaging }\end{array}$ & As conventional drugs & $\begin{array}{l}\text { Packaging leaflet shall reflect the } \\
\text { results of consultations with target } \\
\text { patient groups to ensure that it is } \\
\text { legible, clear and easy to use }\end{array}$ & $\begin{array}{l}\text { Labels should reflect all the necessary } \\
\text { information about the product as guided by } \\
\text { the Australian Therapeutics Goods Act } \\
1989\end{array}$ & $\begin{array}{l}\text { Labeling \& packaging is addressed under } \\
\text { quality control and good manufacturing } \\
\text { practices of the finished product }\end{array}$ \\
\hline $\begin{array}{l}\text { Multi-ingredient } \\
\text { products }\end{array}$ & $\begin{array}{l}\text { Each product must clearly } \\
\text { identified tested separately }\end{array}$ & $\begin{array}{l}\text { Quantitative determination of each } \\
\text { active substance separately }\end{array}$ & $\begin{array}{l}\text { Traditional formulations will normally be } \\
\text { accepted unless current adverse evidence } \\
\text { exists. New formulations should provide } \\
\text { information of efficacy of each herbal } \\
\text { ingredient }\end{array}$ & $\begin{array}{l}\text { Multi-ingredient products not mentioned } \\
\text { directly but the guidelines do mention } \\
\text { formulations of herbal medicines in } \\
\text { quality, safety and efficacy assessment }\end{array}$ \\
\hline
\end{tabular}




\section{REGULATION AND REGISTRATION SYSTEMS FOR TRADITIONAL MEDICINES OF SPECIFIC COUNTRIES AND REGIONS}

Regulations for TCAM in each country serve as a framework for implementation of National Policies and propose a method for registration of TM. The framework of the regulations is intended to simplify and accelerate the registration and standardization of TM and they set out criteria such as pharmaceutical quality, stability testing, safety, therapeutic efficacy, labeling and packaging, multi-ingredients TM, and traditional use. Quality of TM relates to the formulation of the medicines and ensuring consistent quality from batch to batch. Safety specifies that the TM should have higher benefits than risk while efficacy means that the TM should be effective for the indications claimed and should clinically significant and useful. The guidelines are aimed at national drug regulatory authorities, traditional health practitioners (THPs) and institutions involved in TM research and development of related products (WHO, 2004 \& WHO, 2005).

The WHO guidelines for registration of TM in the African region have also classified TM into different categories according to how they are prepared. Category $1 \mathrm{TM}$, are those prepared by THPs for treatment of individual patients and these are normally not regulated by laws of the country but by THPs themselves. Traditional medicines which are widely used in the community, their formulation is known and possible commercial value fall under category 2 TM. The third category caters for TM which have been developed through scientific research. Category 4 TM are imported TM and should meet the requirements for the regulation of TM of the country into which they are being imported into (WHO, 2004). The guidelines for registration of TM in Southeast Asia region under the WHO have a similar structure to those of the African region and this highlights the long history of TM use in both regions (WHO, 2003) (Table 1).

A summary of the requirements for registration of TM in Australia, United States of America (USA), European Union and the WHO African region is presented in Table 1. According to Table 1, the Food and Drug Administration (FDA) of the USA has developed its own draft guidelines for regulation of complementary and alternative medicines (CAM). It has devised four "domains" to classify CAM and TM might fall into 1 or 2 of these domains; either biologically-based practices or whole medical systems. Botanical products fall under biologically-based products which will include the traditional herbal medicines. Any new herbal product identified as treating a specific disease is treated as any new conventional drug and will have to meet similar safety and efficacy requirements (FDA, 2006). The European Medicines Agency (EMEA) has similar registration requirements but also state that the quality of a medicinal product is independent of its traditional use and therefore all general principles of quality apply to traditional herbal medicines for human use (EMEA, 2006a, b; Deal, 2010).

The Australian regulatory guidelines have references to traditional use of herbs or herbal mixtures and to multiingredient products. It states that traditional use is not a substitute for safety but will be considered in the evaluation of efficacy of the herbal medicine. Traditional multi-ingredient products are normally accepted unless current adverse evidence exists. New formulations are assessed as any other new drug (Australian government, 2005a). The WHO guidelines for registration of TM in the African region provide Member States with the framework for development of regulations. Theses guidelines provide the minimum requirements for registration of TM regarding pharmaceutical quality, safety, stability testing, therapeutic efficacy, and labeling and packaging. Because of the diversity of TM types product in Africa, the WHO guidelines has created four (4) categorises TM to simplify the implementation of mechanisms of registration. These categories range from THP remedies prepared for individual patients to TM derived from scientific research (WHO, 2004). Therefore South Africa, as a Member Sate of the WHO, has the necessary framework to develop regulations for registration of TM.

The regulations and guidelines for registration of TM are aimed at all stakeholders, including national drug regulatory authorities; in case of South Africa the Medicines Control Council), Traditional Health Practitioners (THPs), manufacturers and drug research institutions. Traditional health practitioners (THPs) and the TM system of the country therefore need to be developed along with the development and implementation of regulations for registration of TM. This can be achieved by regulating the THP practices and having all THPs registered. This will allow THPs to be part of the processes of development of regulations that will control their medicinal products. This will serve as a great educational tool for the THPs involved in this process and they can in turn deployed to educate other healers. The use of pharmacopoeias and monographs for naming of traditional medicine products will require good understanding from THPs who will want to have their products registered. The idea of involving THPs in all these processes is simply because they are the knowledge holders and their involvement will help to safeguard their intellectual property (IP).

\section{CONSIDERATIONS FOR THE DEVELOPMENT OF GUIDELINES FOR REGISTRATION OF TRADITIONAL MEDICINES IN SOUTH AFRICA}

It is estimated that about $70-80 \%$ of the South African population consults one of the over 200000 THPs for their primary healthcare needs. It is for this reason that there has been recognition of traditional medicine practices in South Africa (Gqaleni et al., 2007; WHO, 2005). It is therefore very regrettable that the TM system is still not yet regulated by law. Some progress has been made by the National Department of Health to provide for a regulatory framework to register, regulate and control THP (THP Act No. 22, 2007). The THP Act will establish an Interim THP Council. The Council will oversee the registration and regulation of the practice of traditional healers by setting practice standards. The establishment of the African Traditional Medicines Expert Committee to advise the MCC is also expected to expedite the process towards development of regulations.

The guidelines being developed in South Africa should also consider the type of TM to be registered. The WHO guidelines for the African region classify TM products into four different categories according to how they are prepared. Category 
1 TM are those remedies prepared by THPs for specific patients during consultations and are not to be regulated (WHO, 2004). The same regulation should be applied in the South African guidelines because such remedies prepared for individual patients change according the presentation of that patient to the healers. Only traditional herbal medicines prepared for commercial sale should be registered and these must follow the registration guidelines of safety, efficacy and pharmaceutical quality. As specified by the EMEA (2006a) and Australian government (2005a), traditional use of the remedy or formulation should be taken into consideration when evaluating safety and efficacy but these should not replace scientific evaluation of claims.

Most TM which claim to provide "effective cures" for various ailments lack scientific evidence of safety, efficacy or pharmaceutical quality. Generally speaking, researchers in the WHO African region lack the facilities for the assessment of quality, safety and efficacy of TM. This is partly because of the complex composition of many TM. South Africa is privileged in that in has the researchers and some facilities to assess the TM products. The National Reference Centre for African Traditional Medicines is an initiative spearheaded by the Department of Health, in partnership with the Council for Scientific and Industrial Research and the Medical Research Council. The centre's remit is to gather, harness and synthesise information to promote, regulate and register African TM of plant origin (Pefile, 2005). Other science councils and universities are also involved in various areas of TM research.

\section{RECOMMENDED STRUCTURE OF THE SOUTH AFRICAN GUIDELINES FOR REGISTRATION OF TRADITIONAL MEDICINES}

The main purpose of implementing the regulation and registration of TM is to protect the consumers of these medicines. But in enforcing these regulations, the authorities must that many pharmaceutical medicines are derived from plants based on the power active compounds they contain (Deal, 2010). Traditional medicines have also been used for centuries in Africa and their regulation is a reversal of the regulatory process for pharmaceutical drugs in that they are already being consumed. In building from the minimum requirements for registration of TM set out by the WHO African region, the South African regulations must take into account the reality of TM being widely used already and the resources available in the country. The more stringent regulatory guidelines of developed countries are mostly aimed at herbal companies while in Africa it is mostly THPs who will have to comply with these regulations. It is these factors and the reality that just because the remedy is a herbal medicine does not mean that the consumer will not suffer side-effects.

It is important to also consider possible interactions between TM and other medicines (Deal, 2010). We have therefore reflected on the regulatory requirements of the FDA, EMA, Australian government and the WHO to come with some recommendations in the development of guidelines for registration of TM in South Africa. These recommendations are meant to minimise the registration requirements while having the best possible impact in protecting the consumer. Our recommendations apply only to traditional herbal medicines as defined by the WHO.

\section{Traditional use}

African TM systems have been in existence for many centuries and conceptual framework is different from that of modern medicine. Traditional use will therefore be used to define herbal medicines which are intended and used without the intervention of medical practitioner for diagnosis, prescription or monitoring of treatment. The use of such medicines must be well established between many THPs over a long time and widely acknowledged. The efficacy must be credible on the basis of long-term use and experience. The botanical identity of the plant must be known and proven through bibliographical evidence. Such evidence can be sourced from handbooks of medicine, pharmacology, pharmacopeias, etc (Deal, 2010; Australian government, 2005a).

\section{Pharmaceutical quality}

Ensuring quality of TM products is a shared responsibility of the MCC and the manufacturers of the products. Requirements for quality control are well covered in the WHO guidelines for registration of TM in the African region (2005). Additional requirements that should be added include ensuring that the raw materials and finished products contain the same amount of active ingredients. Adherence to Good Agricultural and Collection Practice (GACP), Good Laboratory Practice (GLP) and (GMP) must be enforced to ensure pharmacovigilance in collection of raw materials and manufacturing of the finished products. Generally the herbal products must contain the correct ingredients of acceptable ingredients, uncontaminated, and the stated shelf life of the product must be supported by documented evidence. Specifications for the raw and finished products should be provided, identifying physical, chemical and microbiological characteristics of the product and detailing quality control test methods. If the product is a multi-ingredient product, each herbal ingredient in the formulation should be characterized (EMEA, 2006a; Deal, 2010; Australian government, 2005a).

\section{Stability testing}

Stability data produced by the applicant must demonstrate that the product intended for the market will remain safe, of consistent quality and have efficacy throughout its stated shelf life. Since most TM products in their entirety are regarded as active ingredients, the stability of all substances that form part of the final product. This should be determined by appropriate chromatographic fingerprinting and other specific sensory and physical tests. Known active constituents of the product should not 
show a significant variation during the sated shelf life. Products with unknown therapeutic actives which have not been quantified, the stated shelf life should be justified by appropriate chromatographic profiling. Physical characteristics such as colour or odour changes, and precipitation should be also included (EMEA, 2006a; Australian government, 2005 ).

\section{Safety}

Traditional use of TM should not be a substitute for safety but must be taken into consideration when safety is evaluated. Where traditional use is used as safety evidence, the details of use (duration, route, dose etc.) should be consistent with the proposed use. Safety is dependent upon the formulation of the product overall, its intended therapeutic purpose, dosage, route of administration, duration of use, the patient group (such as children, the elderly, and pregnant and lactating women) and possible interactions with critical medication. Where the data documenting a tradition of use is insufficient, or there are suspicions of effects that are difficult or impossible to detect with population or clinical studies, the safety evaluation will need to be supported with other studies (e.g. by in vitro and in vivo single and repeat-dose toxicity, immunotoxicity, reproduction (embryo/fetal, prenatal toxicity), mutagenicity/genotoxicity and carcinogenicity studies) (Deal, 2010; WHO, 2003; Australian government, 2005a).

\section{Therapeutic efficacy}

Long-term use of TM will have to be considered when efficacy is evaluated. Bibliographical evidence from herbal books, pharmacopeias, peer-reviewed scientific papers etc., must be presented along with the application to prove traditional use. When the TM product is used for non-traditional purposes, new evidence must be presented to support the therapeutic use. This evidence can be made up of in vitro and in vivo animal models as a minimum requirement. The type of evidence presented will depend on the kind of indications for use and individual experiences as recorded in reports from physicians, THPs or treated patients (Australian government, 2005a).

New evidence might be required for new formulations of TM. This new evidence should address issues related to pharmacodynamics, pharmacokinetics, bioavailability and possible clinical trials. We recommended that it would be more feasible for THPs to have their TM products evaluated by in vitro and in vivo animal models for their pharmacodynamics, pharmacokinetics, and bioavailability effects. Pharmacodynamics details the possible mechanism of action, dose and dose intervals, and possible drug interactions. Pharmacokinetics describes what happens inside the body once the medicine is taken by the patient and includes the absorptions, distribution, metabolism and elimination. Bioavailability describes the proportion of administered medicine reaching systemic circulation. This is affected by the route of administration of the medicine with intravenous injection taken as $100 \%$ bioavailability (Australian government, 2005b). Clinical trials of TM, although desirable, might not be a feasible requirement for registration of TM from THPs.

\section{Multi-ingredient TM products}

The reality of African TM products is that most of them are made up of different herbs mixed to form one product. Some of the multi-herbal products are based on centuries of knowledge and it is assumed that the ingredients contribute and undefined range and balance of pharmacologically active compounds to their overall therapeutic use. These traditional formulations can be registered based on long-term use unless current adverse evidence exists. New multi-herbal product should have each plant tested separately for quality, safety, efficacy and stability (Australian government, 2005a).

\section{Labeling and packaging}

The WHO guidelines for the African region have very clear requirements for labelling of TM. These cover quantitative listing of active ingredients, identifying the plant names, dosage form, therapeutic indications, manufacturing and expiry date, lot number and the name of the manufacturer (WHO, 2005). Requirements that can be added to these include ensuring that the labels reflect the results of consultations with target patient group groups to ensure that it is legible, clear and easy to use. The aim of this is to demonstrate that patients can understand and know how to act on the instructions of the labeling (Deal, 2010). Packaging should form part of the GMP requirements for manufacturers of TM products. Detailed specifications of the type, nature, size and grade of the primary container should be given including the method of closure and, for liquid products, fill volume (Australian government, 2005b).

\section{Post-approval market monitoring}

National surveillance systems at different levels on the health sector should be put in place in order to monitor and evaluate any reported adverse effects of traditional medicine. This can be done by enhancing the existing national safety monitoring and pharmacovigilance systems to include Traditional Medicine (TM). The objective of the surveillance system will be to provide assurance and consumer confidence in the safety and quality of TM. It will also ensure industry compliance with regulator standards and guidelines for TM. Measures that are to be required to meet the regulations include targeted and 
randomised audits of registered TM, monitoring of suspected adverse events, randomised laboratory testing of TM, monitoring of the market place and an effective, responsive and timely recall procedure. The regulatory authority should also control advertising by approving every advertising campaign of registered TM products (Australian government, 2005a).

\section{PROPOSED ANALYSES TO BE UNDERTAKEN TO ENSURE THE TRADITIONAL MEDICINES MEET BASIC REQUIREMENTS}

The requirements for registration of South African TM should not be beyond the means which could be met by THPs. At the same these requirements should be drafted in such a way that they protect the consumers of TM. Therefore a fine balance must be struck between preserving traditional healing knowledge and meeting the highest standard of health services. It must be said the even the minimum requirements set by WHO for the Africa region are hard to meet for an ordinary THP. Therefore government will have to play an important role in sponsoring the development of TM and traditional healing as a whole. This support will go beyond developing this sector but will need to also to support institutions which will set quality control standards for these requirements. Below we have outlined what we thinking are important minimum requirements that need to be met by TM products in order for them to be registered as medicinal products.

\section{Microorganisms and heavy metal screening- quality control of raw plant material}

Plant materials are naturally exposed to microorganisms and heavy metals which can be found in the environment. The introduction of microbial population in TM (TM) can be either in raw form or finished product; and all of this, depends on the matter in which the plant material is being sampled and prepared and packed. Heavy metal can be indirectly introduced into plant material via natural process or directly as to improve or enhance that particular TM.

Microorganisms are widely distributed in the environment. Traditional medicine(TM) can be contaminated by microorganisms that can be traced back to the bush where samples are being collected, and also during the preparation of plant materials into medicinal plants and storage and packages. Microorganisms have been reported to degrade the quality of some bioactive such as sterols and sterolins which are found in TM (du Plessis-Stoman et al., 2009). In addition, microorganisms like fungi have been known to be produce mycotoxins which are responsible for allergenic compounds (ref). It is necessary for the plant material to be screened of microbial population present in raw plant to preserve the quality of TM.

Heavy metals, such as mercury (Hg), lead $(\mathrm{Pb})$, and arsenic (As), are well-known for their ability to interfere with human health (Weaver et al., 1998; Jarup, 2003; Ljung et al., 2006). Researchers have studies heavy metals' ability to cause chronic effects on human and their potential environmental health hazard, especially in infants and young adults since their respective immune system are not yet fully developed (Hough et al., 2004; Ibrahim et al., 2006; Neuberger et al., 2009). The screening of heavy metals should be included among the standard protocols such as lead, mercury, copper and arsenic in the medicinal plant or finished product due to its abundant in TM as contaminants (Sahoo and Machikanti, 2010).

Phytochemical analysis- quality control of finished products

The importance of TM validation with appropriate tools as to ensure the pool of information about plant material species will not only inform regulations bodies about safety concerning TM, but also will also assist in learning more about bioactive in a particular medicinal plants. The preliminary phytochemical analysis that has been noticeable to be useful tool in the screening of medicinal plants' bioactive is thin layer chromatography (TLC) and has been frequently used (Adewunmi et al., 2001; Alshawsh et al., 2007; Pedersen et al., 2009). High performance liquid chromatography (HPLC) with diode array detection (DAD) has been noted to be promising tool for chemical fingerprinting. The challenges with these technologies are necessary to know standard medicinal plant species with known standard spectrum that will assist in the understanding of unknown peaks (Springfield et al., 2005; du Plessis-Stoman et al., 2009).

\section{Quantitative analysis for safety and efficacy}

It is believed that TM is safe for human used based on the THPs knowledge and experiences working with them and their patients, and often toxicity being reported are associated with miss-identified medicinal plant species. The scientifically validation is necessary to understand safety for those undocumented medicinal plants as to safe-guide consumers with the issues of poisoning by unknown medicinal plants. Various assays has been used in medicinal plant in earl screening of active compounds and assays included antibacterial, antifungal, anti-inflammatory, and antioxidants activity (Pillay et al., 2001; Fennel et al., 2004).

Studies have shown that the screening of medicinal plants with the above-mentioned assays should be pathogenicspecific as to understand the activities medicinal plants have in a particular disease under study (Vuuren, 2008). Langfield et al., (2004) reported on the easy to use and effect method for the identification of antibacterial activities which is modified bioassay method. The measurement outcomes listed below assist in therapeutic or toxic effects analysis of medicinal plants when looking at microbial inhibitory concentrations (MIC), antioxidants properties such as hydroxyl radicals, and anti-inflammatory inhibitors namely: - cyclooxygenase which comes in two isoforms: COX1 and COX2 (Taylor and Staden, 2001; Fennel et al., 2004; Steenkamp et al., 2005). 


\section{Toxicological and pharmacological screening}

The toxicological screening of medicinal plants using human cell lines (in vitro) and animal models (in vivo) will give us some guidance for the selection of highly active plant extract and the results will be provide us with isolation and identification of useful compounds (McGaw et al., 2007). The active compounds are necessary as to understand medicinal plant properties in combating a particular or management of patient well-being. However, it is crucial to take note that TM is more holistic in their approach towards healing processes (Houghton et al., 2007). Pharmacological studies should also be conducted as to have better understand on medicinal plant mode of action (van Wyk, 2008). The safety validation of TM has been looked at with particular interest the following two areas in vitro and in vivo for the analysis of toxic effects of medicinal plant.

It is advisable to ensure that in vitro screenings of medicinal plants are conducted with various dosages as to quantify dose response curve. Various cytotoxicity assays has been used and the choice depend on the outcomes needed to be measured based on a disease being studied or what the medicinal plant is targeting to treat. The measurement outcomes that can be undertaken in bioassays can include cell proliferation, cell morphology, and plasma membrane, cell signaling, cell differentiation, metabolism, DNA replication and apoptosis (Popat et al., 2001; Saad et al., 2006). The advantages of bioassay are designed to produce accurate results of high quality within short period of time, furthermore, most test are colometric so it easy to observe some changes if any during the experiment.

Animals such as mice and rats are being in vitro experimentation can be either be acute or sub chronic toxicity analysis. Acute toxicity is an observational study where animal are being given different dosages and monitored for their behavioral and physiological are timed within the period of the experiment. Animals are being sacrificed at the end of the experiment which takes with maximum of 14 days and vital organs are tested for toxicity (Soulimani et al., 2001; Déciga-Campos, et al., 2007). Unlike sub-chronic toxicity where rats are being used for this experiment can run up to 90 days, but suitable period is 60 days as to avoid rats being stressed by the experimentation. The observational changes are also recorded here with blood sample being taken in specified period and analyzed; and at the end of the experimentation period rats are being sacrificed and vital organs are measured such as liver, kidney, spleen and ovaries/ testes (Lu et al., 2005; Khader et al., 2010). In addition to the test mentioned here above lung pathology, hematology, plasma biochemistry and cytokines production can also be measured after experimentation (Jung et al., 2004; Amresh et al., 2008).

\section{Acknowledgements}

Professor Gqaleni is the South African Research Chair in Indigenous Health Care Systems, sponsored by the Department of Science and Technology (DST) and administered by the National Research Foundation (NRF). The views expressed here do not reflect those of the DST/NRF.

\section{References}

1. Adewumi, G.O., Agbedahunsi, J.M., Adebayo. A.C., Aladesanmi. A.J., Murphy. N., Wando, J. (2001). Screening of Nigerian Medicinal Plants for Trypanocidal Properties. J. Ethnopharmacol., 77:19-24.

2. Alshawsh, M.A., Mothana, R.A., Al-shamahy, H.A., Alsllami, S.F., Lindequist, U. (2007). Assessment of antimalarial activity against Plasmodium falciparum and phytochemical screening of some Yemeni medicinal plants. Evid. Based Complement. Alternat. Med., 6(4): 453456.

3. Amresh, G., Singh, P.N., Venkateswara, R. (2008). Toxicological screening of traditional medicine Laghupatha (Cissampelos pariera) in experimental animals. J. Ethnopharmacol. 116(3): 454-460.

4. Australian government, Department of Health and Ageing, Therapuetic Goods Administration, (2005a). Australian regulatory guidelines for complementary medicines (ARGCM) part IV: general guidance.

5. Australian government, Department of Health and Ageing, Therapuetic Goods Administration, (2005b). Australian regulatory guidelines for complementary medicines (ARGCM) part I: registration of complementary medicines.

6. Cowan, M.M. (1999). Plant products as antimicrobial agents. Clin. Micro. Rev., 12(4): 564-582.

7. Deal, G. (2010). Overview and update on EU directive 2004/24/EC: traditional herbal medicines. Reg. Rapporteur 7(7/8): 10-14.

8. Déciga-Campos, M., Rivero-Cruz, I., Arriaga-Alba, M., Castaneda-Corral, G., Angeles-Lopez, G.E., Navarrete, A., Mata, R. (2007). Acute toxicity and mutagenic activity of Mexican plants used in traditional medicine. J. Ethnopharmacol. 110: 334-342.

9. du Plessis-Stoman, D., Downing, T.G., van der Venter, M., Govender, S. (2009). Traditional herbal medicines: potential degradation of sterols and sterolins by microbial contaminants. S. Afr. J. Sci., 105(3/4): 147-150.

10. European Medicines Agency, (2006a). Guideline on quality of herbal medicinal products/traditional herbal medicinal products. EMEA/CVMP/814/00 Rev 1.

11. European Medicines Agency, (2006b). Guidelines on specifications: test procedures and acceptance criteria for herbal substances, herbal preparations and herbal medicinal products/traditional herbal medicinal products. EMEA/CVMP/815/00 Rev 1.

12. Fennell, C.W., Lindsey, K.L., McGaw, L.J., Sprag, S.G., Staffort, G.I., Elgorashi, E.E., Grace, O.M., Van Staden, J. (2004). Assessing African medicinal plants for efficacy and safety: pharmacological screening and toxicity. J. Ethnopharmacol., 94: 205-217.

13. Gqaleni, N., Moodley, I., Kruger, H., Ntuli, A., and McLeod, H. (2007). In: Harrison , S., Bhana, R., Ntuli, A., editors. South African Health Review 2007. Durban: Health Systems Trust. pp175-188

14. Hough, R.L., Breward, N., Young, S.D., Crout, N.M.J., Tye, A.M., Moir, A.M., Thornton, I. (2004). Assessing potential risk of heavy metal exposure from consumption of home-produced vegetables by urban populations. Environ. Health. Perspect., $112(2): 215-221$. 
15. Houghton, P.J., Howes, M.-J., Lee, C.C., Steventon, G. (2007). Uses and abuses of in vitro tests in ethnopharmacology: visualizing an eelephant. J. Ethnopharmacol. 110:391-400.

16. Ibrahim, N.A., El-Naggar, G. O. (2006). Assessment of heavy metals levels in water, sediment and fish at cage fish culture at Damietta Branch of the river Nile. J. Egypt. Acad. Environ. Develop., 7 (1): 93-1114.

17. Jarup, L. (2003). Hazards of heavy metal contamination. Br. Med. Bull., 68(1): 167-182.

18. Jung, K., Kim, I-H., Han, D. (2004). Effects of medicinal plant extracts on forced swimming capacity in mice. J. Ethnopharmacol. 93(1): 75-81.

19. Khader, M., Bresgen, N., Eckl, P.M. (2010). Antimutagenic effects of ethanolic extracts from selected Palestinian medicinal plants. J. Ethnopharmacol. 127:319-324.

20. Langfield, R.D., Scarano, F.J., Heitzman, M.E., Kondo, M., Hammond, G., Neto, C. (2004). Use of a modified microplate bioassay method to investigate antibacterial activity in the Peruvian medicinal plant Peperomia galioides. J. Ethnopharmacol., 94: $279-281$.

21. Ljung, K., Selinus, O., Otabbong, E. (2006). Metals in soils of children's urban environments in the small northern European city of Uppsala. J. Sci. Tot. Environ., 366(2/3): 749-759.

22. Lu, B., Wu, X., Tie, X., Zhang, Y., Zhang, Y. (2005). Toxicology and safety of anti-oxidant of bamboo leaves. Part 1: acute and subchronic toxicity studies on anti-oxidant of bamboo leaves. Food Chem. Tox. 43(5): 783-792.

23. McGaw, L.J., van der Merwe, D., Eloff, J.N. (2007). In vitro anthelmintic, antibacterial and cytotoxic effects of extracts from plants used in South Africa ethnoveterinary medicine. Vet. J. 173:366-372.

24. Mills, E., Cooper, C., Seely, D., Kanfer, I. (2005). African herbal medicines in the treatment of HIV: Hypoxis and Sutherlandia. An overview of evidence and pharmacology. Nutr. J. 4: 19.

25. Neuberger, J.S., Hu, S.C., Drake, K.D., Jim, R. (2009). Potential health impacts of heavy-metal exposure at the Tar Creek Superfund site, Ottawa County, Oklahoma. Environ. Geochem. Health., 31:47-59.

26. Pedersen, M. M., Chukwujekwu, J. C., Lategan, C. A., van Staden, J., Smith, P. J., Staerk, D. (2009). Antimalarial sesquiterpene lactones from Distephanus angulifolius. Phytochem., 70: 601-607.

27. Pefile, S. (2005). South African legislation on traditional medicine. Sci. Dev. Network.

28. Pillay, C.C.N., Jäger, A.K., Mulholland, D.A., van Staden, J. (2001). Cyclooxygenase inhibiting and antibacterial activities of South African Erythrina species. J. Ethnopharmacol., 74: 231-237.

29. Popat, A., Shear, N.H., Malkiewicz, I., Stewart, M.J., Steenkamp, V., Neuman, M.G. (2001). The toxicity of Callilepis laureola, a South African traditional herbal medicine. Clin. Biochem. 34(3): 229-236.

30. Saad, B., Azaizeh, H., Abu-Hijleh, G., Said, O. (2006). Safety of traditional Arab herbal medicine. eCAM 3(4): $433-439$.

31. Sahoo, N. and Machikanti, P. (2010). Herbal drugs: standards and regulations. Fitoter., 81:462-471.

32. Soulimani, R., Younos, C., Jarmouni-Idrissi, S., Bousta, D., Khalouki, F., Laila, A. (2001). Behavioral and pharmaco-toxicological study of Papaver rhoeas L. in mice. J. Ethnopharmacol. 74:265-274.

33. Springfield, E.P., Eagles, P.K.F., Scott, G. (2005). Quality assessment of South African herbal medicines by means of HPLC fingerprinting. J. Ethnopharmacol., 101: 75-83.

34. Steenkamp, V., Mathivha, E., Gouws, M.C., van Rensburg, C.E.J. (2005). Studies on antibacterial, antioxidant and fibroblast growth stimulation of wound healing remedies from South Africa. J. Ethnopharmacol. 95: 353-357.

35. Taylor, J.L.S., van Staden, J. (2001). COX-1 inhibitory activity in extracts from Eucomis L'Herit. species. J. Ethnopharmacol., 75: $257-265$.

36. United States Department of Health and Human Services, Food and Drug Administration, (2006). Guidance for industry on Complementary and Alternative Medicine (CAM) products and their regulation by the Food and Drug Administration: draft guidance.

37. van Vuuren, S.F. (2008). Antimicrobial activity of South African medicinal plants. J. Ethnopharmacol., 119: 465-472.

38. van Wyk, B.-E. (2008). A broad review of commercially important southern African medicinal plants. J. Ethnopharmacol. 119:342355.

39. Weaver, L.M., Gan, S., Quirino, B., Amasino, R.M. (1998). A comparison of the expression patterns of several senescence-associated genes in response to stress and hormone treatment. Plant Mol. Biol., 37: 455-469.

40. World Health Organization Regional Office for Africa, (2001). Promoting the role of traditional medicine in health systems. A strategy for the African region. AFR/RC50/9.

41. World Health Organization Regional Office for Africa, (2004). Guidelines for registration of TM in the WHO African region. AFR/TRM/04.1.

42. World Health Organization Regional Office for South-East Asia, (2003). Guidelines for regulation of herbal medicines in the SouthEast Asian region. SEA.Trad. Med.-82.

43. World Health Organization, (2005). National policy on traditional medicine and regulation of herbal medicines: Report of a WHO global survey 